\title{
Saccharin aversions induced by lithium chloride toxicosis in a backward conditioning paradigm*
}

\author{
FRED J. BOLAND \\ Memorial University of Newfoundland, St. Johns, Newfoundland, Canada
}

\begin{abstract}
Seven experimental groups of seven rats each were allowed to consume saccharin solution at different times relative to intubation of lithium chloride solution. Six backward conditioning (BWD) groups were intubed $0.5,1,2,3,4$, and $8 \mathrm{~h}$ before saccharin consumption, and a forward conditioning (FWD) group was intubed $0.5 \mathrm{~h}$ after saccharin consumption. A no-lithium control group of 14 rats received no intubation. Only the $0.5-\mathrm{h}$ FWD and the 0.5-h BWD groups showed an aversion to saccharin relative to the no-lithium controls. The aversion to saccharin in the $0.5-\mathrm{h} F W D$ group was more pronounced than that in the 0.5-h BWD group. This shows that the aversive effects of lithium toxicosis dissipate far sooner than the aversive effects of X-irradiation.
\end{abstract}

If ingestion of a flavored substance, such as saccharin solution, is followed by toxicosis induced by some independent means, such as $\mathrm{X}$-irradiation, rats will avoid the flavored substance on subsequent occasions (Revusky \& Garcia, 1970). With saccharin. this is true even if the interval between ingestion and exposure is extended up to $12 \mathrm{~h}$ (Smith \& Roll, 1967). Furthermore, it has been shown that rats will form an aversion to saccharin solution when the solution is consumed up to $12 \mathrm{~h}$ after exposure to radiation ceases (Scarborough, Whaley, \& Rogers, 1964). It was initially suspected that the reduced preference was due to unlearned factors (McLaurin, 1964), or to backward conditioning, which is generally considered impossible (Kimble, 1961). A better explanation is that the aversive physiological aftereffects of the radiation continue Inng after exposure ceases (Scarborough et al, 1964; Smith, Taylor, Morris, \& Hendricks, 1965; Revusky \& Garcia, 1970). Thus, although the operational paradigm may involve backward conditioning, consumption of the saccharin solution may well precede the peak of the sickness.

Lithium chloride is the most effective known chemical toxicosis for producing flavor aversions in animals (Nachman \& Ashe, in press). Nachman (1970) has shown that forward conditioning can take place when the interval between saccharin consumption and lithium toxicosis is up to at least $4 \mathrm{~h}$. However, the backward conditioning curve for lithium has not been investigated. The best guess is that the backward curve for lithium would be much shorter than that for $\mathrm{X}$-irradiation. In radiation sickness with humans, the prodromal symptoms of nausea and vomiting do not become pronounced until approximately $7 \mathrm{~h}$ after radiation (Gerstner, 1960). According to reports of investigators who themselves consumed lithium, lithium

\footnotetext{
*The author wishes to thank Dr. Sam Revusky whose advice facilitated and whose NRC Grant No. A8271 supported this study. Requests for reprints should be sent to Fred J. Boland, Department of Psychology, Memorial University of Newfoundland, St. Johns, Newfoundland, Canada.
}

sickness lasts approximately $2 \mathrm{~h}$ and has a sharper peak than radiation sickness; within 10.20 min of this peak, which is correlated with the peak lithium concentration in the blood, all symptoms disappear (Trautner, Morris, Noack, \& Gershon, 1955). Thus, although there is no guarantee that the absorption pattern of lithium is identical for humans and rats, the human data offer a strong hint that the backward curve will be much shorter for lithium than for X-irradiation. The present experiment deals with the extent of an aversion to saccharin solution which may occur if lithium is intubed directly into the stomachs of rats at various intervals prior to consumption of the saccharin solution.

\section{METHOD}

\section{Subjects and Preexperimental Preparation}

Two strains of rats were used to increase generality. They consisted of 36 adult male Sprague-Dawleys familiar with sucrose from a previously unrelated $T$-maze experiment and 27 naive adult male Fisher inbreds. All animals were gentled and housed in individual home cages where food was available except on the day of conditioning. Four Sprague-Dawleys and three Fishers were assigned randomly to each of seven experimental groups, leaving eight and six, respectively, for controls. Six days before conditioning, all animals were placed on a water-deprivation schedule designed to insure rapid and complete consumption of a saccharin solution on the day of conditioning. All Ss received $1 \mathrm{~h}$ of water on Day $1,0.5 \mathrm{~h}$ on Day 2, and $10 \mathrm{~min}$ on Days 3, 4, and 5. Water was introduced at a regular time in stainless steel cups attachable to the cages. To insure empty stomachs and therefore rapid absorption of the lithium, food was removed $8 \mathrm{~h}$ before treatment started.

\section{Conditioning and Recovery}

On Day 6, all experimental groups received identical intubations (for procedure, see Braveman \& Capretta, 1965) of $20 \mathrm{ml} / \mathrm{kg}$ of .3 molar $(1.27 \%)$ lithium chloride solution. Intubation times differed for each group relative to consumption of $3 \mathrm{ml}$ of $0.5 \%$ saccharin solution at their regular drinking time. Six backward conditioning (BWD) groups were intubed $0.5,1,2$, 3,4 , and $8 \mathrm{~h}$ before saccharin consumption, and one forward conditioning (FWD) group was intubed $0.5 \mathrm{~h}$ after saccharin was introduced. Controls received no intubation. Food and water were returned to the Ss $16 \mathrm{~h}$ after consumption of the saccharin solution. and a $24-h$ period of recovery followed. Due to 


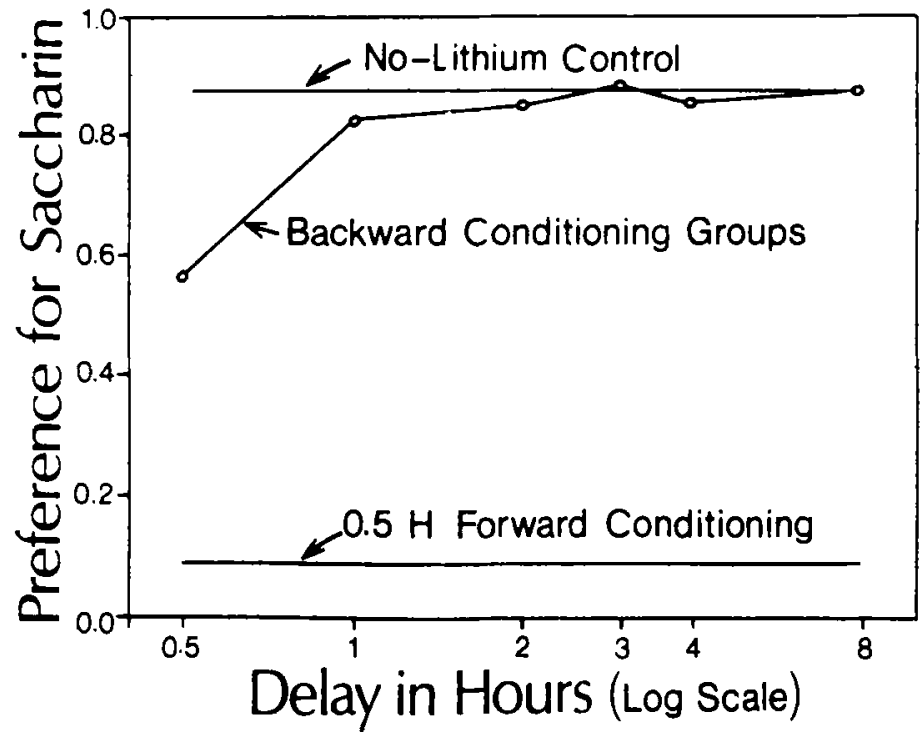

improper intubation, one Sprague-Dawley from the 3-, 4-, and 8-h BWD groups and one Fisher from the 0.5-h FWD group died.

\section{Testing}

On Day 8, a 48-h two-bottle choice test between saccharin solution and tap water began. The water bottles were weighed and placed on the left position of the cage front. At the same time, previously weighed bottles of 0.5 s saccharin solution were placed in the right position. Every $12 \mathrm{~h}$, the bottles were weighed and the positions of the two bottles were interchanged. Preference for saccharin was computed by dividing the total saccharin consumed by the total fluid consumed.

\section{RESULTS AND DISCUSSION}

The two strains differed in overall preference for saccharin by only $0.3 \%$ and were pooled for statistical purposes. No extinction was observed, and the saccharin preference for each group was averaged over the four test sessions. In Fig. 1, the no-lithium controls and the 0.5-h FWD group are represented by straight lines. The only groups to show an aversion to saccharin solution relative to the controls were the $0.5-\mathrm{h}$ FWD group $(t=$ $14.35, \mathrm{df}=18, \mathrm{p}<.0001)$ and the $0.5-\mathrm{h} \mathrm{BWD}$ group $(\mathrm{t}=$ 3.31 , $\mathrm{df}=19, \mathrm{p}<.005)$. Furthermore, the aversion obtained in the 0.5 -h FWD group was much greater than that in the 0.5-h BWD group $(\mathrm{t}=3.21$, df $=17$, $p<.005)$. None of the other groups yielded significantly lower preferences than did the controls, the largest being the 1 -h BWD group $(t=.693, d f=19, p \gg .05)$. These results agree with an independent study by Domjan and Wilson (in press). They noted that one of their control groups introduced to saccharin solution $1.5 \cdot 3 \mathrm{~h}$ after injection of lithium chloride did not form an aversion.

In conclusion, the aversive effects of lithium chloride toxicosis dissipate far sooner than toxicosis induced by $\mathrm{X}$-irradiation. If consumption of saccharin solution is delayed by more than $0.5 \mathrm{~h}$ after intubation of lithium chloride solution, rats will not form a flavor aversion.
Fig. 1. Mean preference for saccharin solution relative to tap water among six BWD groups as a function of the delay between intubation of lithium chloride and subsequent ingestion of saccharin solution. The mean preferences for the no-lithium controls and a $1 / 2-h$ FWD group are shown as horizontal lines.

\section{REFERENCES}

Braveman, N. S., \& Capretta, P. J. The relative effectiveness of two experimental techniques for the modification of food preferences in rats. Proceedings of the 73rd Annual Convention of the American Psychological Association, 1965, 129-130.

Domjan, M., \& Wilson, N. E. The contribution of ingestive behaviors to taste-aversion learning in the rat. Journal of Comparative \& Physiological Psychology, in press.

Gerstner, H. B. Reactions to short-term radiation in man. A nnual Review of Medicine, 1960, 11, 289-302.

Kimble, G. A. Hilgard and Marquis' conditioning and learning. (2nd ed.) New York: A ppleton-Century-Crofts, 1961.

McLaurin, W. A. Postirradiation saccharin avoidance in rats as a function of the interval between ingestion and exposure. Journal of Comparative \& Physiological Psychology, 1964, 57, 316-317.

Nachman, M. Learned taste and temperature aversions due to lithium chloride sickness after temporal delays. Journal of Comparative \& Physiological Psychology. 1970, 73, 31-37.

Nachman, M., \& Ashe. Learned taste aversions in rats as a function of dosage, concentration and route of administration of lithium chloride. Physiology \& Behavior, in press.

Revusky, S. H., \& Garcia, J. Learned associations over long delays. In G. H. Bower (Ed.), Psychology of learning and motivation: Advances in research and theory. New York: Academic Press, 1970. Pp. 1-83.

Scarborough, B. B., Whaley, D. L., \& Rogers, J. G. Saccharin-avoidance behavior instigated by X-irradiation in backward conditioning paradigms. Psychological Reports, $1964,14,475-481$.

Smith, J. C., \& Roll, D. L. Trace conditioning with $\mathrm{X}$-rays as the aversive stimulus. Psychonomic Science, 1967, 9, 11-12.

Smith, J. C., Taylor, H. L., Morris, D. D., \& Hendricks. J. Further studies of X-ray conditioned saccharin aversion during the post exposure period. Radiation Research, 1965, 24, 423-431.

Trautner, E. M., Morris, R., Noach, C. H., \& Gershon, S. The excretion and retention of ingested lithium and its effects on the ionic balance in man. Medical Journal of Australia, 1955, 42, 280-291.

(Received for publication August 3, 1972; revision received October $2,1972$. 